\title{
VERIFICAÇÃO DE SEGURANÇA E DIMENSIONAMENTO DE REFORÇO EM FIBRA DE CARBONO EM ESTRUTURA DE CONCRETO ARMADO
}

\author{
Carlos Eduardo Courradesqui de Araujo \\ Pós-graduando em Engenharia Estrutural pela UNISUAM, Rio de Janeiro, RJ, Brasil. \\ carloscourradesqui@gmail.com
}

Eduardo Gullo de Assis Pós-graduando em Engenharia Estrutural pela UNISUAM, Rio de Janeiro, RJ, Brasil. edugullo@gmail.com

Igor Charlles Siqueira Leite Mestre em Engenharia Civil (UFRJ), Professor do Centro Universitário Augusto Motta (UNISUAM - RJ) Rio de Janeiro, RJ, Brasil igorcharlles@souunisuam.com.br

Niemeyer Torqueti Junior Pós-graduando em Engenharia Estrutural pela UNISUAM, Rio de Janeiro, RJ, Brasil. Niemeyer.torquetti@gmail.com

\section{RESUMO}

Ao longo dos anos, é comum que estruturas com vida útil mais avançadas apresentem anomalias e desgastes naturais, em sua maioria, provenientes da falta de manutenção. Contudo, a ineficiência do comportamento estrutural, não compete apenas à falta de manutenção, como também está associada às falhas executivas, análises e verificações estruturais errôneas ou uma alteração na utilização da edificação, provocando um acréscimo de carregamento não previsto inicialmente na etapa de concepção do modelo estrutural. Desse modo, se faz necessário a intervenção da estrutura, visando reabilitar o comportamento estrutural de forma satisfatória através da técnica de reforço estrutural. O presente trabalho teve por objetivo a verificação de segurança de uma estrutura em concreto armado e apresentação de solução proposta em fibra de carbono. O estudo se inicia com uma breve revisão bibliográfica sobre o conceito de reforço estrutural em fibra de carbono. Seguidamente é explanado o estudo de caso, apresentando as características da edificação, prospecções realizadas in loco para levantamento de informações necessárias a continuidade do trabalho, prosseguindo então com a verificação de segurança e capacidade resistente dos elementos. Apresentando por fim, o dimensionamento do reforço estrutural em fibra de carbono. Com isto pretende-se apresentar, de uma maneira prática, o estudo de caso, as etapas e critérios de verificação de segurança estrutural bem como o dimensionamento do reforço estrutural em fibra de carbono.

Palavras-chave: Reforço Estrutural; Fibra de Carbono; Estrutura de Concreto Armado, Verificação de Segurança.

\section{SAFETY VERIFICATION AND SIZING OF CARBON FIBER REINFORCEMENT IN REINFORCED CONCRETE STRUCTURE}

\begin{abstract}
Over the years, it is common for structures with more advanced lifespans to present anomalies and natural wear, mostly due to lack of maintenance. However, the inefficiency of the structural behavior is not only due to the lack of maintenance, but is also associated with executive failures, erroneous previous analyzes and verifications or a change in the use of building, causing an increase in unforeseen loading of design stage in a structural model. That way, it's necessary the intervention of the structure, aiming to rehabilitate
\end{abstract}


the structural behavior in a satisfactory way through the technique of structural reinforcement. The present work aimed to verify the safety of a reinforced concrete structure and to present a proposed solution in carbon fiber. The study begins with a brief bibliographical review on the concept of structural reinforcement in carbon fiber. The case study is then explained, adding the characteristics of the building, surveys carried out in loco to gather information necessary for the continuity of the work, then proceeding with the verification of the safety and resistance capacity of the elements. Finally, presenting the dimensioning of the structural reinforcement in carbon fiber. With this, it is intended to present in a practical way, the case study, the steps and criteria of verification of structural safety, as well as the dimensioning of the structural reinforcement in carbon fiber.

Keywords: Structural reinforcement; Carbon fiber; Concrete structure; Security check.

\section{INTRODUÇÃO}

Por definição, na construção civil, o reforço estrutural é caracterizado pela intervenção em uma estrutura existente, aumentando sua capacidade resistente antes de atingir o seu estadolimite. Tais reforços podem ser executados por técnicas e procedimentos distintos, porém o objeto de estudo deste presente artigo é apresentar a técnica de reforço estrutural por fibra de carbono em uma laje de uma edificação já existente.

Apesar do alto custo do material em si, a tomada de decisão por tal escolha se justifica por ser material com extraordinária resistência mecânica, possuir bom comportamento à fadiga e à atuação de cargas cíclicas, elevada resistência a ataques químicos diversos, não são afetados pela corrosão (produto inerte), possui estabilidade térmica e reológica e extrema leveza, devido ao baixo peso específico do sistema (de $1,6 \mathrm{~g} / \mathrm{cm}^{3}$ à $1,9 \mathrm{~g} / \mathrm{cm}^{3}$, cerca de 5 vezes menor do que o aço estrutural).

Outro fator condicionante e que acaba reduzindo o custo final de tal técnica de reforço é o tempo e a facilidade de execução da mesma, que neste caso justifica-se pela aplicação em uma construção já edificada. Este edifício possui em sua totalidade, grande parte dos projetos complementares executados (hidráulica, elétrica, rede, incêndio e outros), além disso, quase todas as lajes apresentam o teto rebaixado de gesso acartonado, desta maneira, esses fatores foram relevantes ao optar-se pela adoção da fibra de carbono, tornando sua execução mais simples, sem intervir de forma abrupta no que já foi executado.

Sendo assim, o objetivo do presente estudo foi, após verificar as condições de segurança da estrutura, dimensionar o reforço estrutural com fibra de carbono de uma laje do pavimento tipo de uma edificação comercial de 7 pavimentos, em estrutura de concreto armado, localizada no município do Rio de Janeiro, RJ. 


\section{DESENVOLVIMENTO}

\subsection{Revisão bibliográfica}

\subsubsection{Reforço estrutural}

É importante ressaltar que existe uma diferença entre reparo estrutural e reforço estrutural. No reparo estrutural, o objetivo é o restabelecimento das características mecânicas iniciais (devolve-se à estrutura danificada sua capacidade resistente inicial). Já no reforço estrutural, o objetivo é o estabelecimento de características mecânicas superiores às iniciais, ou seja, a capacidade resistente da estrutura é aumentada.

As etapas do projeto de reparo ou reforço estrutural podem ser descritas como:

a) Diagnóstico do problema e medidas emergenciais;

b) Viabilidade do projeto;

c) Investigação, ensaios não destrutivos ou semi-destrutivos;

d) Reanálise, rigidez - redistribuição;

e) Seleção da técnica e dos materiais de reparo ou reforço;

f) Projeto, cálculo e detalhamento;

g) Execução e controle de qualidade.

\subsubsection{FIBRA DE CARBONO}

As fibras de carbono são resultado do tratamento térmico, a carbonização, de fibras precursoras orgânicas tais como o poliacrilonitril (PAN) ou com base no alcatrão derivado do petróleo ou do carvão (PITCH) em um ambiente inerte e, também, através de fibras de rayon. 0 processo de fabricação consiste na oxidação dessas fibras precursoras seguidas de um, processo a altas temperaturas, podendo variar de $1000^{\circ} \mathrm{C}$ a $1500^{\circ} \mathrm{C}$ para as fibras de carbono e até $3000^{\circ} \mathrm{C}$ para fibras de grafite.

Com o processo térmico, as fibras resultantes apresentam os átomos de carbono perfeitamente alinhados ao longo da fibra precursora, característica que oferece extraordinária resistência mecânica ao produto final.

Quanto maior a temperatura em que o processo é realizado, maior será o módulo de elasticidade do material final, que pode variar de 100GPa a 300GPa para fibras de carbono e até 650GPa para fibras de grafite. Quanto maior o módulo de elasticidade do material resultante, 
maior seu custo. O produto com o módulo de elasticidade maior (grafite) pode custar cerca de 15 a 20 mais que o produto de fibra de carbono.

Figura 1 - Diagrama Tensão x Deformação das fibras

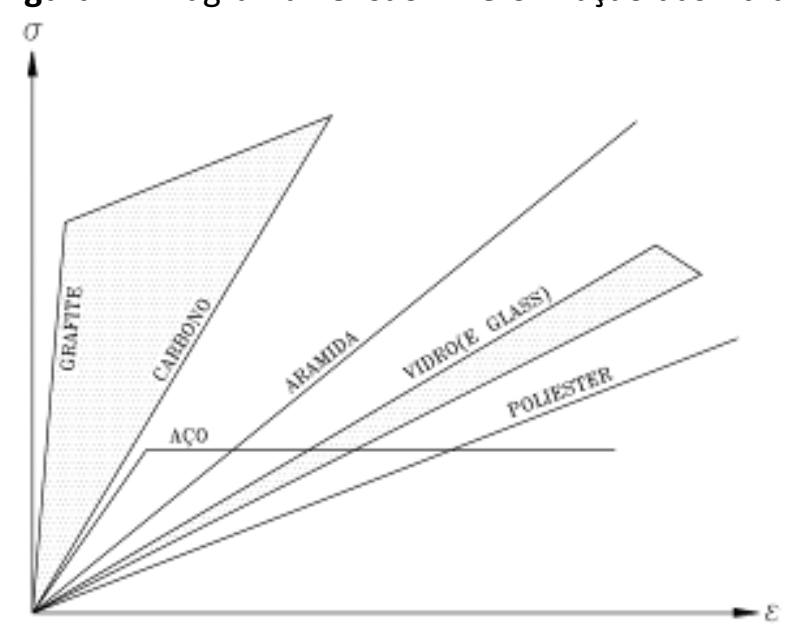

Fonte: (Manual VIAPOL)

O coeficiente de dilatação térmica dos compostos unidirecionais de carbono varia segundo suas direções longitudinal e transversal e dependem do tipo da fibra, da resina, e do volume de fibra de carbono

Tabela 1 - Coeficientes de dilatação das fibras de carbono.

\begin{tabular}{|l|c|}
\hline \multicolumn{1}{|c|}{ Direção } & Coeficiente de Dilatação Térmica \\
\hline Longitudinal $\left(\alpha_{\mathrm{L}}\right)$ & $-10^{-6} /{ }^{\circ} \mathrm{C}$ a 0 \\
\hline Transversal $\left(\alpha_{\mathrm{T}}\right)$ & $22 \times 10^{-6} /{ }^{\circ} \mathrm{C}$ a $23 \times 10^{-6} /{ }^{\circ} \mathrm{C}$ \\
\hline
\end{tabular}

(Fonte: Autor)

$\mathrm{O} \mathrm{ACl} 440$ indica, genericamente, para sistemas compostos estruturados com fibra de carbono, CFC, as seguintes propriedades:

Tabela 2 - Características genéricas das fibras de carbono

\begin{tabular}{|l|l|l|l|}
\hline \multicolumn{1}{|c|}{$\begin{array}{c}\text { Tipo de Fibra de } \\
\text { Carbono }\end{array}$} & $\begin{array}{c}\text { Módulo de } \\
\text { Elasticidade } \\
\text { (GPa) }\end{array}$ & $\begin{array}{c}\text { Resistência } \\
\text { Máxima de Tensão } \\
\text { (MPa) }\end{array}$ & $\begin{array}{l}\text { Deformação } \\
\text { de Ruptura } \\
\text { (\%) }\end{array}$ \\
\hline De uso geral & $220-235$ & $<3.790$ & $>1,2$ \\
\hline Alta resistência & $220-235$ & $3.790-4.825$ & $>1,4$ \\
\hline Ultra alta resistência & $220-235$ & $4.825-6.200$ & $>1,5$ \\
\hline Alto módulo & $354-515$ & $>3.100$ & $>0,5$ \\
\hline Ultra alto módulo & $515-690$ & $>2.410$ & $>0,2$ \\
\hline
\end{tabular}

Fonte: (Autor)

Os sistemas compostos estruturados com fibras de carbono (CFC) são confeccionados com dois elementos distintos e fundamentais:

\begin{tabular}{l|l|l|l|l|l|l} 
Projectus | Rio de Janeiro | & V.5 & N. 1 & P. $36-53$ & | & 2020
\end{tabular}


a) A matriz polimérica, que tem a função de manter a estrutura que compõe as fibras de maneira coesa, de modo, a propiciar a transferência das tensões de cisalhamento entre os dois elementos estruturais, concreto e fibra de carbono;

b) O elemento estrutural, constituído pelas fibras de carbono. As fibras são arranjadas unidirecionalmente dentro das matrizes poliméricas e absorvem as tensões de tração decorrentes dos esforços solicitantes atuantes.

Figura 2 - Esquema de um sistema de fibras de carbono.

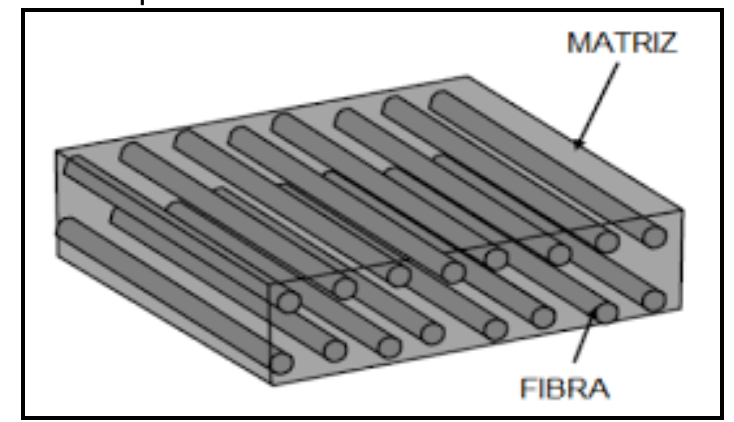

Fonte: (Manual VIAPOL)

A matriz polimérica necessariamente tem que ter um alongamento de ruptura muito maior do que o alongamento que ocorre na fibra de carbono, para permitir que a mesma continue a possuir capacidade de carga mesmo após a tensão na fibra ter atingido a sua tensão de ruptura. Para tanto, os sistemas compostos com fibras de carbono devem trabalhar segundo o critério fibra com ruptura frágil e matriz polimérica com ruptura dúctil.

Figura 3 - Diagramas tensão $x$ deformação para matrizes poliméricas.
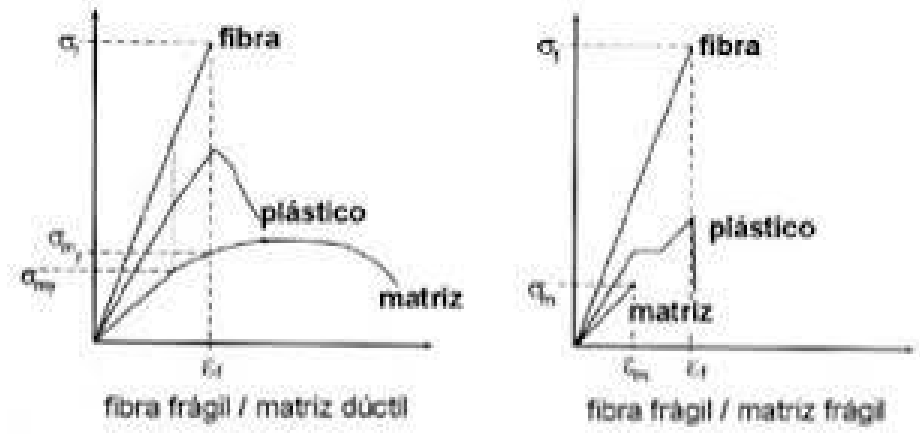

Fonte: (Manual VIAPOL)

A sequência para execução dos sistemas compostos com fibras de carbono pode ser resumida em:

- Recuperação do substrato de concreto armado para que o sistema possa ser aderido com segurança; 
- Imprimação da superfície sobre a qual será aplicado o sistema para se estabelecer uma ponte de aderência entre o substrato de concreto e o sistema composto. Para tanto utiliza-se um imprimador epoxídico (primer) com elevado teor de sólidos que, ao penetrar nos poros do concreto e ao estabelecer uma película sobre a superfície do concreto, cria uma interface altamente eficiente para a transmissão de esforços entre o composto e a peça de concreto.

- Regularização e correção das imperfeições superficiais do substrato de concreto, de modo a estabelecer um plano adequadamente nivelado. É utilizado uma pasta epoxídica contendo alto teor de sólidos para calafetar eventuais imperfeições superficiais e criar um plano desempenado para a aplicação do sistema composto.

- Aplicação da primeira camada de resina saturante com alto teor de sólidos que servirá para saturar a lâmina de fibra de carbono e aderi-la à superfície do concreto.

- Aplicação da lâmina de fibra de carbono que vai reforçar o composto.

- Aplicação da segunda camada de resina saturante para completar a impregnação da lâmina de fibra de carbono e acabando de conformar a matriz epoxídica que envelopa o sistema.

- Aplicação de maneira opcional de uma película de acabamento com alto teor de sólidos, alto brilho e resistência a corrosão, com a objetivo de proteção e/ou acabamento estético para o sistema.

Figura 4 - Etapas construtivas dos sistemas compostos estruturados de fibra de carbono.

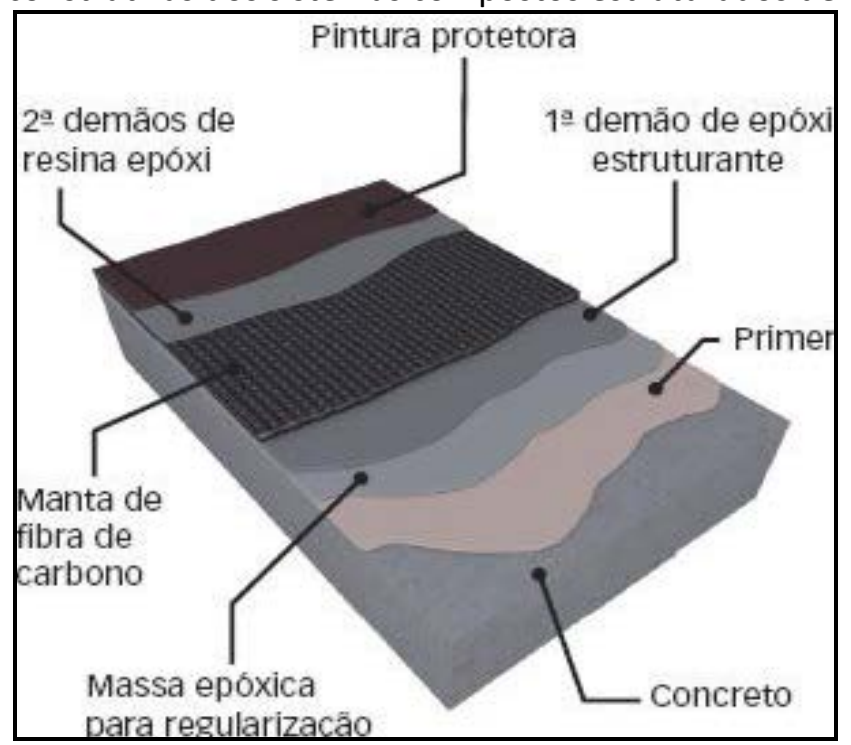

(Fonte: Manual VIAPOL) 


\subsection{ESTUDO DE CASO}

A edificação estudada no presente trabalho, trata-se de um prédio comercial de 7 pavimentos, situada no município do Rio de Janeiro. A estrutura é de concreto armado, com o prédio se dividindo em um subsolo, pavimento de acesso, 4 pavimentos tipo e cobertura, totalizando uma área total construída de aproximadamente $2.000 \mathrm{~m}^{2}$.

O estudo se fez necessário pois houveram mudanças significativas em relação ao projeto inicial, na qual apresentava uma solução convencional, compreendendo um sistema em concreto armado com painéis de lajes maciças retangulares, vigas e pilares. Na revisão do projeto original, em especial nos pavimentos tipo e cobertura, houve a eliminação da maioria das vigas internas, passando-se a utilizar o sistema de lajes planas, aumentando a espessura das lajes e criando capitéis nos casos mais críticos. Esta nova solução foi emprega na construção da edificação.

Realmente, nas últimas décadas é comum obras prediais projetadas com a solução estrutural de pavimentos em laje plana (lisa). Comumente denominadas "lajes cogumelo", as lajes planas (lisas) se distinguem dos sistemas tradicionais com a supressão de vigas e com a transferência de carga diretamente aos pilares, na forma de apoios discretos (pontuais). Não obstante as suas diversas vantagens técnicas e econômicas, do ponto de vista estrutural, lajes cogumelo vêm se tratar de uma solução mais sofisticada, exigindo um maior nível de recursos de projeto para um preciso controle do seu funcionamento, inclusive no que concerne o aspecto de deformabilidade dos pavimentos e de todo o conjunto.

Não foi disponibilizado o memorial de cálculo da nova solução e dentre os documentos disponíveis, foram identificados importantes divergências tais como detalhamento de armaduras dos elementos estruturais, locação de capitéis e disposições construtivas que não respeitam os critérios da boa prática de construção, o que ocasionalmente abre margem para um aumento de erros durante a etapa de execução.

Diante do exposto, fez-se necessário verificações numéricas afim de avaliar a segurança estrutural da edificação e, caso não atendesse aos seus respectivos estados limites preconizados por critérios normativos, seria dimensionado reforço estrutural.

Para tanto, a fim de se obter mais informações que complementassem as informações já em posse e tornassem as análises mais refinadas, foram feitas prospecções in loco, em locais estratégicos, identificando armaduras, seções dos elementos estruturais, cobrimento e espessura de revestimentos. 
Figuras 5 e 6 - Prospecção para identificação de armaduras da laje
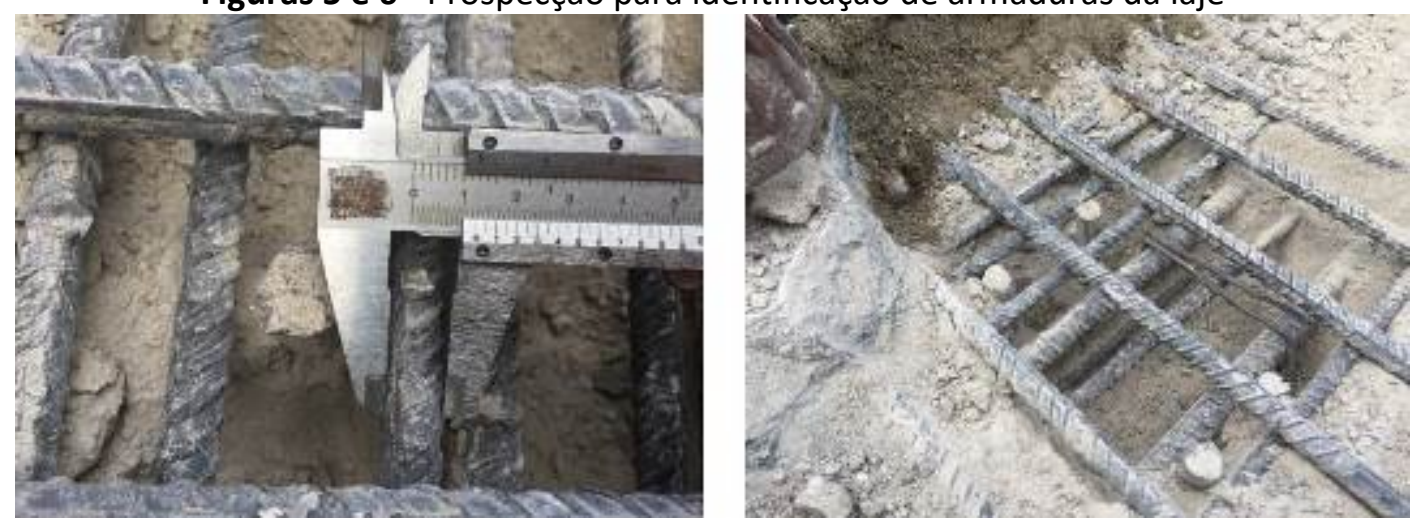

Fonte: (Autor)

\subsection{Avaliação da segurança da estrutura}

Para que se obtivesse uma visão mais ampla sobre a segurança da estrutura, houve a necessidade de realizar um trabalho mais amplo, com o processamento integral da mesma. Para tanto, utilizou-se o software TQS na versão V22.3, com a obtenção dos esforços considerando a discretização do pavimento com elementos de barra, ortogonais, configurando uma grelha.

A verificação de segurança da estrutura foi feita inicialmente considerando as condições normais de carregamento, seguindo as informações constantes nos desenhos do Projeto de arquitetura fornecidos pelo proprietário.

Em relação às cargas, as principais premissas adotadas nos estudos de verificação de segurança são as que se seguem:

A. Cargas Permanentes Adotadas (G)

- Peso Próprio $\rightarrow$ Calculado automaticamente pelo software considerando o peso específico do concreto de $2,50 \mathrm{tf} / \mathrm{m}^{3}$.

- Contrapiso (pavimento tipo) $\rightarrow 0,10 \mathrm{tf} / \mathrm{m}^{2}$, correspondente à espessura média de 5 centímetros.

- Piso elevado + Forro $\rightarrow 0,05 \mathrm{tf} / \mathrm{m}^{2}$.

- Alvenarias Internas $\rightarrow 0,57 \mathrm{tf} / \mathrm{m}$, correspondente à alvenaria de blocos de concreto de $9 \mathrm{~cm}$ de espessura e revestimentos em ambas as faces de $2,0 \mathrm{~cm}$.

- Alvenarias Periféricas $\rightarrow 0,45 \mathrm{tf} / \mathrm{m}$, correspondente à alvenaria de blocos de concreto de $14 \mathrm{~cm}$ de espessura e revestimentos em ambas as faces de 1,5 cm.

B. Cargas Acidentais Adotadas (Q)

- Pavimentos Tipo - 0,25 tf/m² em todo o pavimento.

- Cobertura -0,40 tf/m $/ \mathrm{m}^{2}$ em todo o pavimento 
Quanto aos materiais, consideramos:

- Concreto com resistência característica a compressão de $30 \mathrm{MPa}\left(300 \mathrm{kgf} / \mathrm{cm}^{2}\right)$, valor indicado nos desenhos do projeto estrutural;

- Aço com tensão de escoamento igual a $500 \mathrm{MPa}\left(f_{\mathrm{yk}}=5000 \mathrm{kgf} / \mathrm{cm}^{2}\right)$;

Foram adotadas as seguintes Normas Técnicas:

- ABNT NBR 8800:2008 - Projeto de estruturas de aço e de estruturas mistas de aço e concreto de edifícios;

- ABNT NBR 6120:2019 - Ações para o cálculo de estruturas de edificações;

- $\quad$ ABNT NBR 6123:1988 - Força devido ao vento em edificações

- ABNT NBR 8681:2004 - Ações e segurança nas estruturas - Procedimento;

\subsection{Capacidade resistente das lajes}

Para a determinação da capacidade resistente das lajes, foram consideradas, além dos materiais já informados, as armaduras detalhadas nos desenhos do projeto estrutural modificado. Foram definidas faixas de acordo com as armaduras existentes, conforme apresentado nas imagens seguintes.

Para cada uma das faixas foi calculada capacidade resistente da seção, comparando os valores desta forma obtidos com os resultantes do processamento, tanto para as cargas totais como apenas para as permanentes.

Figura 7- Armaduras positivas, sentido transversal.

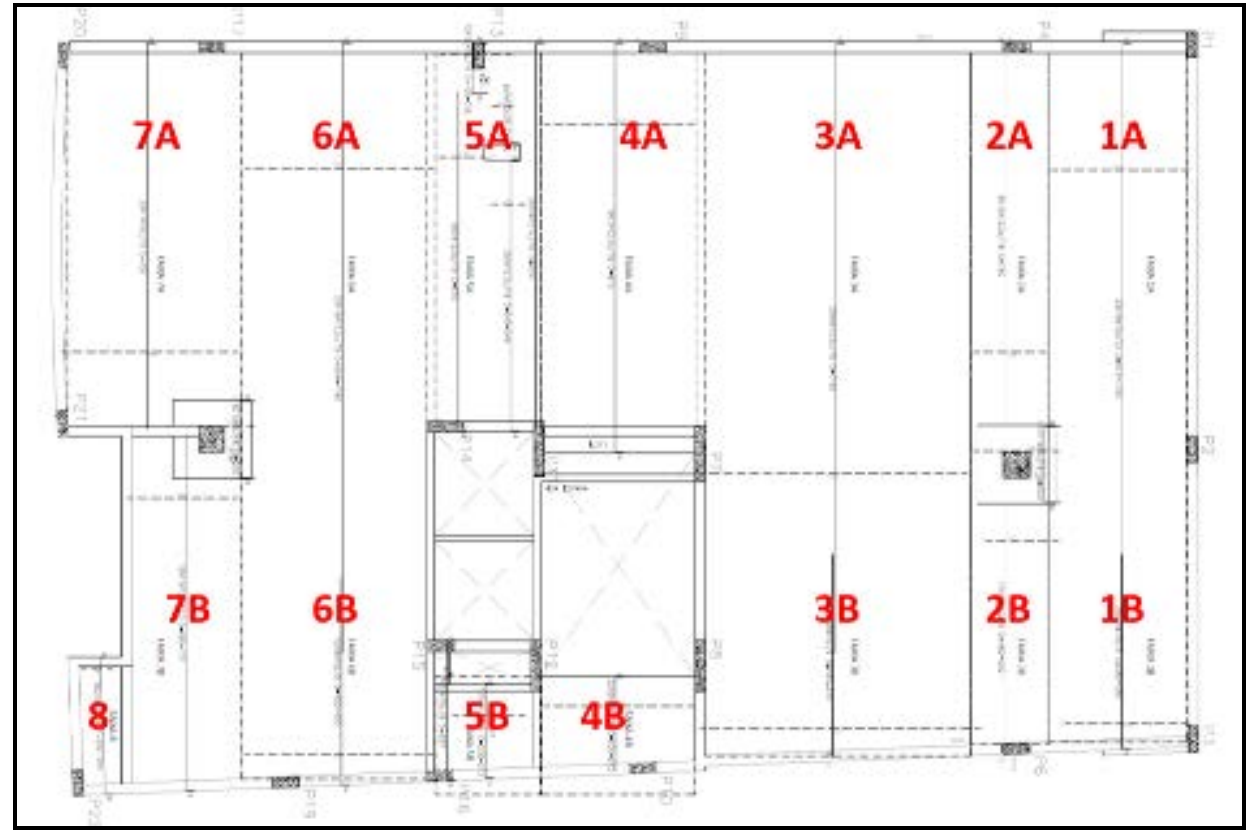

Fonte: (Autor) 
Figura 8 - Armaduras negativas, sentido transversal

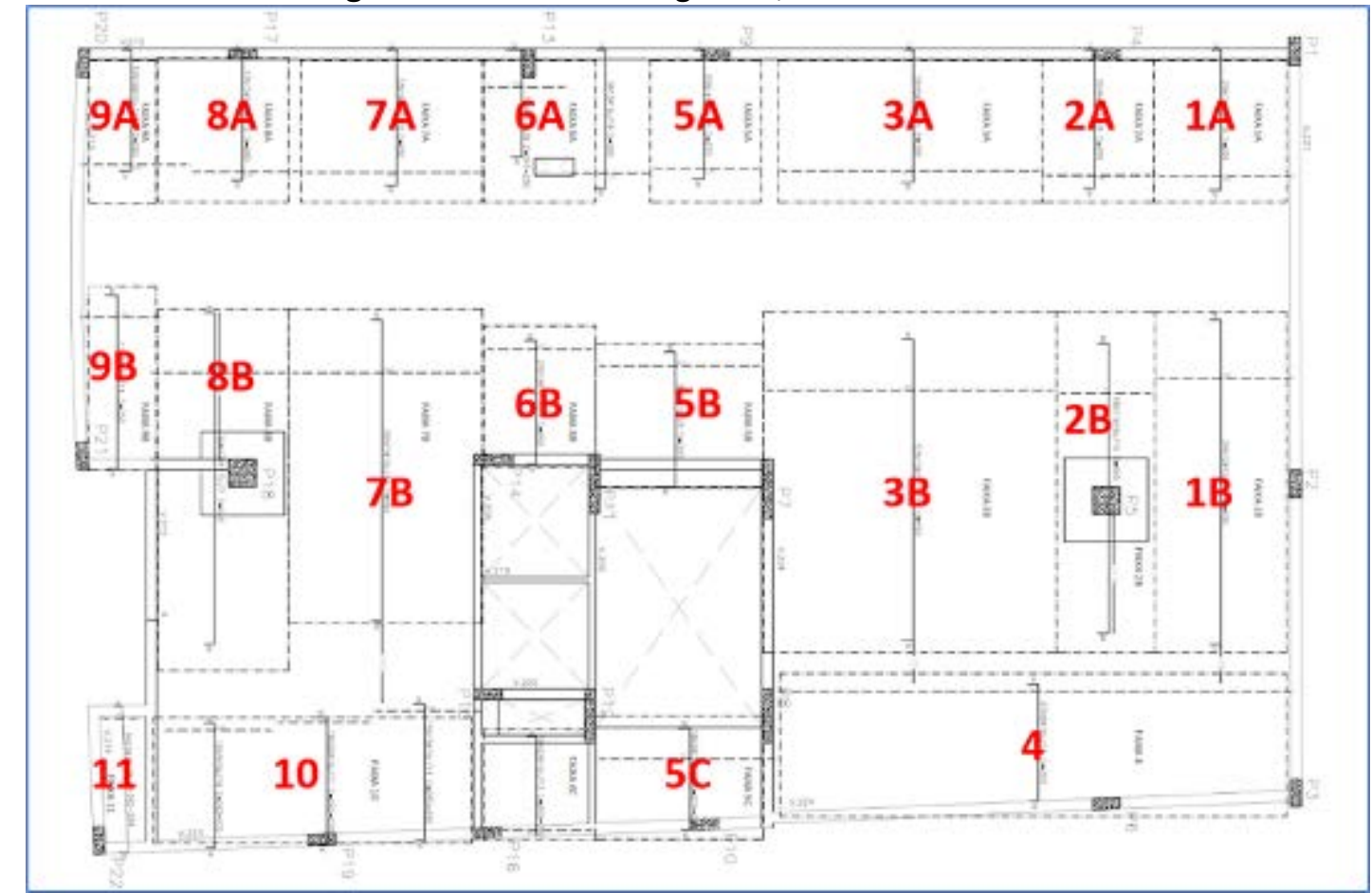

Fonte: (Autor)

Figura 9 - Armaduras positivas, sentido longitudinal

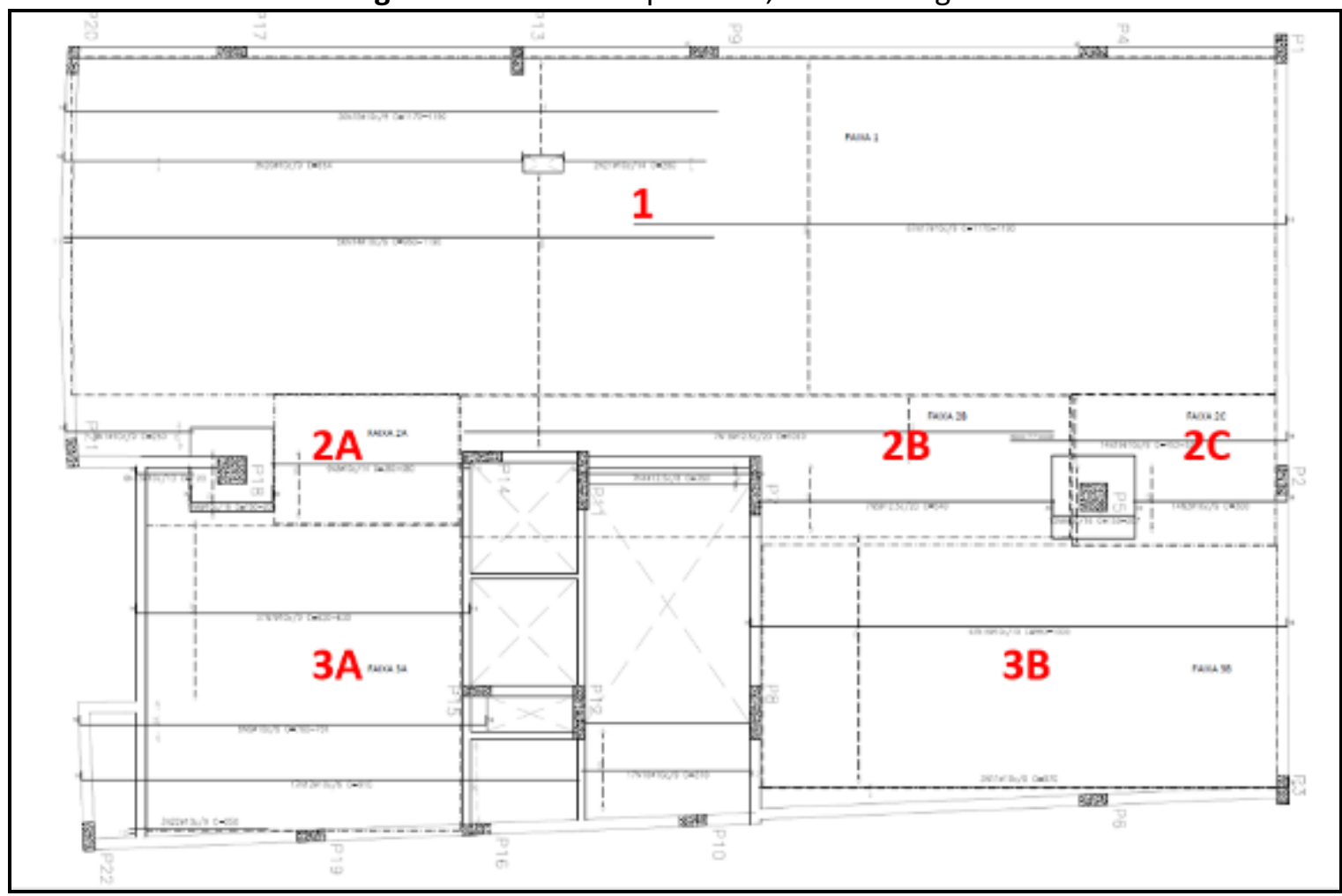

Fonte:(Autor) 
Figura 10 - Armaduras negativas, sentido longitudinal

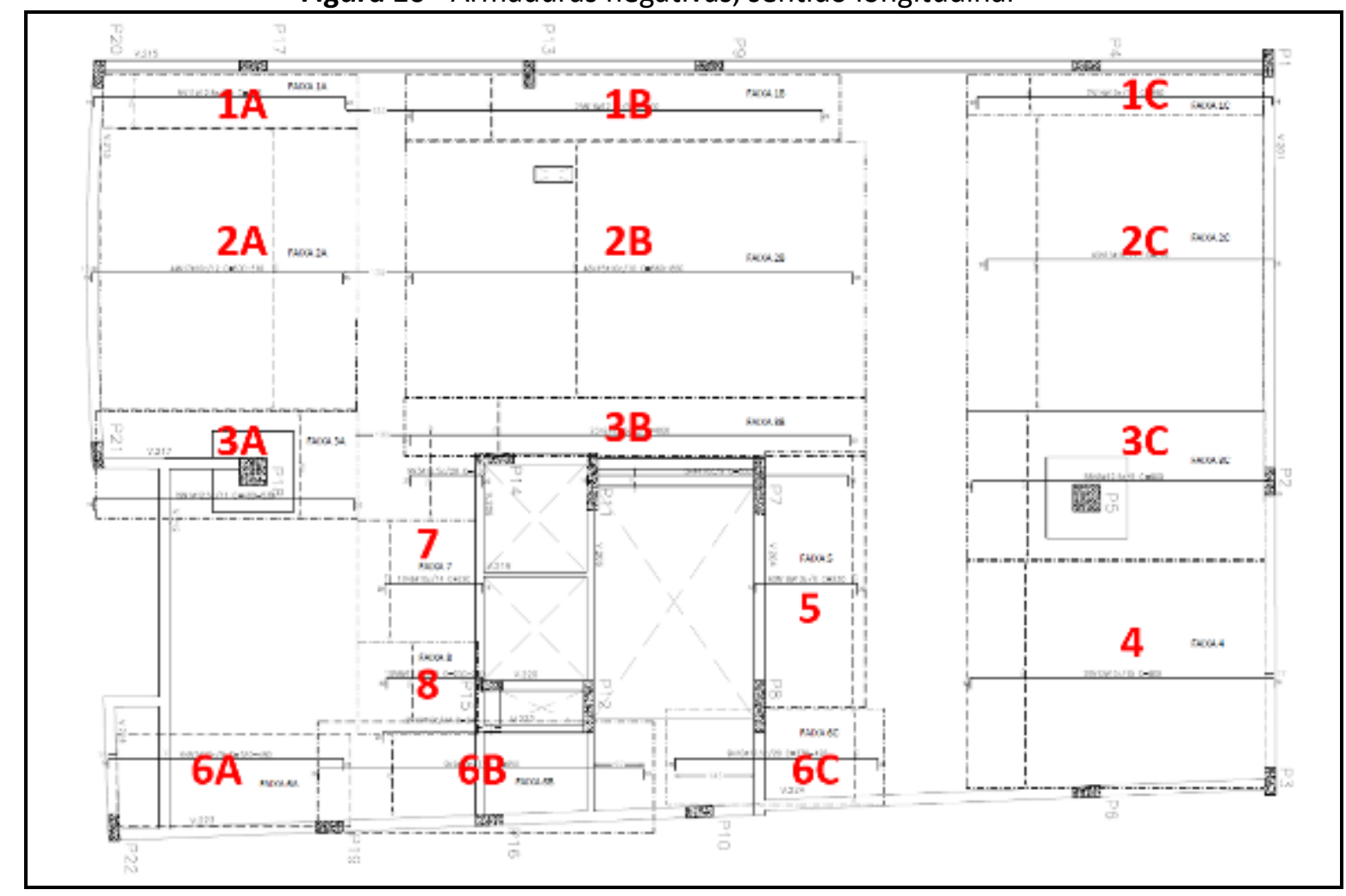

Fonte: (Autor)

As tabelas a seguir apresentadas mostram os valores obtidos nos cálculos para a determinação da capacidade resistente das lajes.

Tabela 3 - Momentos Resistentes e Admissíveis das Lajes - Flexão Positiva, Sentido Transversal.

\begin{tabular}{|c|c|c|c|c|c|c|c|c|c|c|}
\hline Direção & Local & $\emptyset(\mathrm{mm})$ & Espaçamento $(\mathrm{cm})$ & $\mathrm{f}_{\mathrm{yk}}\left(\mathrm{kgf} / \mathrm{cm}^{2}\right)$ & $\mathrm{f}_{\mathrm{ck}}\left(\mathrm{kgf} / \mathrm{cm}^{2}\right)$ & $b_{w}(c m)$ & $\mathrm{d}(\mathrm{cm})$ & $A_{s}\left(\mathrm{~cm}^{2} / \mathrm{m}\right)$ & $M_{\text {res }}(t f . c m / m)$ & $\mathrm{M}_{\mathrm{adm}}(\mathrm{tf} . \mathrm{cm} / \mathrm{m})$ \\
\hline \multirow{9}{*}{ 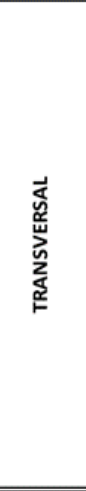 } & Faixa $1 \mathrm{~A}$ & 10 & 12 & 5000 & 300 & 100 & 18,0 & 6,54 & 485,1 & 346,5 \\
\hline & Faixa 1B & 10 & 9 & 5000 & 300 & 100 & 18,0 & 8,73 & 639,9 & 457,1 \\
\hline & Faixa 2A & 12,5 & 18 & 5000 & 300 & 100 & 18,0 & 6,82 & 505,3 & 360,9 \\
\hline & Faixa 3B & 10 & 9 & 5000 & 300 & 100 & 18,0 & 8,73 & 639,9 & 457,1 \\
\hline & Faixa 4A & 12,5 & 16 & 5000 & 300 & 100 & 18,0 & 7,67 & 566,0 & 404,3 \\
\hline & Faixa $4 B$ & 10 & 14 & 5000 & 300 & 100 & 18,0 & 5,61 & 417,5 & 298,2 \\
\hline & Faixa 5A & 12,5 & 18 & 5000 & 300 & 100 & 18,0 & 6,82 & 505,3 & 360,9 \\
\hline & Faixa 5B & 10 & 9 & 5000 & 300 & 100 & 18,0 & 8,73 & 639,9 & 457,1 \\
\hline & Faixa 6A & 12,5 & 19 & 5000 & 300 & 100 & 18,0 & 6,46 & 478,7 & 341,9 \\
\hline
\end{tabular}

Fonte: (Autor) 
Tabela 4 - Momentos Resistentes e Admissíveis das Lajes - Flexão Negativa, Sentido

Transversal

PAVIMENTO TIPO (2\%, 3, 4\%)

\begin{tabular}{|c|c|c|c|c|c|c|c|c|c|c|}
\hline \multirow[t]{2}{*}{ Direção } & \multirow[t]{2}{*}{ Local } & \multicolumn{2}{|c|}{ Armadura Existente } & \multirow[t]{2}{*}{$f_{y k}\left(\mathrm{kgf} / \mathrm{cm}^{2}\right)$} & \multirow[t]{2}{*}{$f_{c k}\left(\mathrm{kgf} / \mathrm{cm}^{2}\right)$} & \multirow[t]{2}{*}{$\mathbf{b}_{\mathrm{w}}(\mathrm{cm})$} & \multirow[t]{2}{*}{$\mathrm{d}(\mathrm{cm})$} & \multirow[t]{2}{*}{$A_{s}\left(\mathrm{~cm}^{2} / \mathrm{m}\right)$} & \multirow[t]{2}{*}{$\mathbf{M}_{\text {res }}(\mathrm{tf} . \mathrm{cm} / \mathrm{m})$} & \multirow[t]{2}{*}{$M_{\mathrm{adm}}(\mathrm{tf} . \mathrm{cm} / \mathrm{m})$} \\
\hline & & $\varnothing(\mathrm{mm})$ & Espaçamento $(\mathrm{cm})$ & & & & & & & \\
\hline & \multicolumn{10}{|c|}{ Flexão Negativa } \\
\hline & Faixa 1A & 10 & 10 & 5000 & 300 & 100 & 18,0 & 7,85 & 577,8 & 412,7 \\
\hline & Faixa 1B & 10 & 10 & 5000 & 300 & 100 & 18,0 & 7,85 & 577,8 & 412,7 \\
\hline & Faixa 2A & 12,5 & 8 & 5000 & 300 & 100 & 18,0 & 15,34 & 1074,5 & 767,5 \\
\hline & Faixa 2B - Laje (face do capitel) & 16 & 10 & 5000 & 300 & 100 & 18,0 & 20,11 & 1358,0 & 970,0 \\
\hline & Faixa 2B - Ca pitel (face do pilar) & 16 & 10 & 5000 & 300 & 100 & 38,0 & 20,11 & 2866,8 & 2047,7 \\
\hline & Faixa $3 \mathrm{~A}$ & 10 & 14 & 5000 & 300 & 100 & 18,0 & 5,61 & 417,5 & 298,2 \\
\hline & Faixa 3B & 12,5 & 10 & 5000 & 300 & 100 & 18,0 & 12,27 & 878,3 & 627,4 \\
\hline & Faixa 4 & 10 & 14 & 5000 & 300 & 100 & 18,0 & 5,61 & 417,5 & 298,2 \\
\hline & Faixa 5A & 12,5 & 8 & 5000 & 300 & 100 & 18,0 & 15,34 & 1073,9 & 767,0 \\
\hline & Faixa 5B & 16 & 8 & 5000 & 300 & 100 & 18,0 & 25,13 & 1630,6 & 1164,7 \\
\hline & Faixa 5C & 10 & 19 & 5000 & 300 & 100 & 18,0 & 4,13 & 310,2 & 221,6 \\
\hline & Faixa 6A-Laje (face do capitel) & 16 & 8 & 5000 & 300 & 100 & 18,0 & 25,13 & 1630,6 & 1164,7 \\
\hline & Faixa 6A-Ca pitel (face do pilar) & 16 & 8 & 5000 & 300 & 100 & 38,0 & 25,13 & 3442,3 & 2458,8 \\
\hline & Faixa 6B & 12,5 & 9 & 5000 & 300 & 100 & 18,0 & 13,64 & 965,2 & 689,4 \\
\hline & Faixa 6C & 10 & 13 & 5000 & 300 & 100 & 18,0 & 6,04 & 449,6 & 321,2 \\
\hline & Faixa 7A & 10 & 10 & 5000 & 300 & 100 & 18,0 & 7,85 & 577,8 & 412,7 \\
\hline & Faixa 7B & 10 & 10 & 5000 & 300 & 100 & 18,0 & 7,85 & 577,8 & 412,7 \\
\hline & Faixa $8 \mathrm{~A}$ & 12,5 & 12 & 5000 & 300 & 100 & 18,0 & 10,23 & 742,7 & 530,5 \\
\hline & Faixa 8B - Laje (face do capitel) & 12,5 & 7 & 5000 & 300 & 100 & 18,0 & 17,53 & 1208,7 & 863,4 \\
\hline & Faixa 8B-Capitel (face do pilar) & 12,5 & 7 & 5000 & 300 & 100 & 38,0 & 17,53 & 2551,8 & 1822,7 \\
\hline & Faixa 9A & 10 & 17,5 & 5000 & 300 & 100 & 18,0 & 4,49 & 336,8 & 240,6 \\
\hline & Faixa 9B & 10 & 14 & 5000 & 300 & 100 & 18,0 & 5,61 & 417,5 & 298,2 \\
\hline & Faixa 10 & 10 & 11 & 5000 & 300 & 100 & 18,0 & 7,14 & 526,9 & 376,4 \\
\hline & Faixa 11 & 10 & 9 & 5000 & 300 & 100 & 18,0 & 8,73 & 639,9 & 457,1 \\
\hline
\end{tabular}

Fonte: (Autor)

Tabela 5 - Momentos Resistentes e Admissíveis das Lajes - Flexão Positiva e Negativa, Sentido Longitudinal

\begin{tabular}{|c|c|c|c|c|c|c|c|c|c|c|}
\hline \multirow[t]{2}{*}{ Direção } & \multirow[t]{2}{*}{ Local } & \multicolumn{2}{|c|}{ Armadura Existente } & \multirow[t]{2}{*}{$f_{\mathrm{yk}}\left(\mathrm{kgf} / \mathrm{cm}^{2}\right)$} & \multirow[t]{2}{*}{$f_{c k}\left(\mathrm{kgf} / \mathrm{cm}^{2}\right)$} & \multirow[t]{2}{*}{$\mathbf{b}_{\mathrm{w}}(\mathrm{cm})$} & \multirow[t]{2}{*}{$\mathrm{d}(\mathrm{cm})$} & \multirow[t]{2}{*}{$A_{s}\left(\mathrm{~cm}^{2} / \mathrm{m}\right)$} & \multirow[t]{2}{*}{$M_{\text {res }}(\mathrm{tff} . \mathrm{cm} / \mathrm{m})$} & \multirow[t]{2}{*}{$M_{\text {adm }}(t \mathrm{tf} . \mathrm{cm} / \mathrm{m})$} \\
\hline & & $\emptyset(\mathrm{mm})$ & Es paçamento $(\mathrm{cm})$ & & & & & & & \\
\hline & \multicolumn{10}{|c|}{ Flexão Negativa } \\
\hline & Faixa $1 \mathrm{~A}$ & 10 & 10 & 5000 & 300 & 100 & 18,0 & 7,85 & 577,8 & 412,7 \\
\hline & Faixa $1 \mathrm{~B}$ & 10 & 10 & 5000 & 300 & 100 & 18,0 & 7,85 & 577,8 & 412,7 \\
\hline & Faixa 2A & 12,5 & 8 & 5000 & 300 & 100 & 18,0 & 15,34 & 1074,5 & 767,5 \\
\hline & Faixa 2B - Laje (face do capitel) & 16 & 10 & 5000 & 300 & 100 & 18,0 & 20,11 & 1358,0 & 970,0 \\
\hline & Faixa 2B - Ca pitel (face do pilar) & 16 & 10 & 5000 & 300 & 100 & 38,0 & 20,11 & 2866,8 & 2047,7 \\
\hline & Faixa $3 \mathrm{~A}$ & 10 & 14 & 5000 & 300 & 100 & 18,0 & 5,61 & 417,5 & 298,2 \\
\hline & Faixa 3B & 12,5 & 10 & 5000 & 300 & 100 & 18,0 & 12,27 & 878,3 & 627,4 \\
\hline & Faixa 4 & 10 & 14 & 5000 & 300 & 100 & 18,0 & 5,61 & 417,5 & 298,2 \\
\hline & Faixa 5A & 12,5 & 8 & 5000 & 300 & 100 & 18,0 & 15,34 & 1073,9 & 767,0 \\
\hline & Faixa 5B & 16 & 8 & 5000 & 300 & 100 & 18,0 & 25,13 & 1630,6 & 1164,7 \\
\hline & Faixa 5C & 10 & 19 & 5000 & 300 & 100 & 18,0 & 4,13 & 310,2 & 221,6 \\
\hline & Faixa 6A- Laje (face do capitel) & 16 & 8 & 5000 & 300 & 100 & 18,0 & 25,13 & 1630,6 & 1164,7 \\
\hline & Faixa 6A-Capitel (face do pilar) & 16 & 8 & 5000 & 300 & 100 & 38,0 & 25,13 & 3442,3 & 2458,8 \\
\hline & Faixa 6B & 12,5 & 9 & 5000 & 300 & 100 & 18,0 & 13,64 & 965,2 & 689,4 \\
\hline & Faixa $6 \mathrm{C}$ & 10 & 13 & 5000 & 300 & 100 & 18,0 & 6,04 & 449,6 & 321,2 \\
\hline & Faixa 7A & 10 & 10 & 5000 & 300 & 100 & 18,0 & 7,85 & 577,8 & 412,7 \\
\hline & Faixa 7B & 10 & 10 & 5000 & 300 & 100 & 18,0 & 7,85 & 577,8 & 412,7 \\
\hline & Faixa $8 \mathrm{~A}$ & 12,5 & 12 & 5000 & 300 & 100 & 18,0 & 10,23 & 742,7 & 530,5 \\
\hline & Faixa 8B - Laje (face do capitel) & 12,5 & 7 & 5000 & 300 & 100 & 18,0 & 17,53 & 1208,7 & 863,4 \\
\hline & Faixa 8B - Capitel (face do pilar) & 12,5 & 7 & 5000 & 300 & 100 & 38,0 & 17,53 & 2551,8 & 1822,7 \\
\hline & Faixa 9A & 10 & 17,5 & 5000 & 300 & 100 & 18,0 & 4,49 & 336,8 & 240,6 \\
\hline & Faixa 9B & 10 & 14 & 5000 & 300 & 100 & 18,0 & 5,61 & 417,5 & 298,2 \\
\hline & Faixa 10 & 10 & 11 & 5000 & 300 & 100 & 18,0 & 7,14 & 526,9 & 376,4 \\
\hline & Faixa 11 & 10 & 9 & 5000 & 300 & 100 & 18,0 & 8,73 & 639,9 & 457,1 \\
\hline
\end{tabular}

Fonte: Autor)

\subsection{Verificação de segurança das lajes}

A verificação de segurança das lajes foi realizada em duas etapas, com a primeira delas comparando os momentos fletores atuantes, oriundos da ação conjunta de todas as cargas, com

\begin{tabular}{l|l|l|l|l|l|l} 
Projectus | Rio de Janeiro & V.5 & N. 1 & P. $36-53$ & 2020
\end{tabular} 
os momentos resistentes. O quociente resultante da divisão de ambos os valores é que indica o nível de segurança da seção em estudo.

A segunda etapa considerou a comparação dos momentos resistentes com os solicitantes resultantes da ação única das cargas permanentes. Esta comparação nos fornece o grau de segurança das lajes na situação atual, com apenas as cargas permanentes atuantes. Os valores estão representados pelos números na segunda coluna, da esquerda para a direita.

De fato, de acordo com a NBR 6118:2014, o esforço resistente de cálculo deve ser, no mínimo, igual ao esforço solicitante de cálculo, como se pode ver a seguir, em trecho extraído da própria norma.

Figura 11 - NBR 6118:2014.

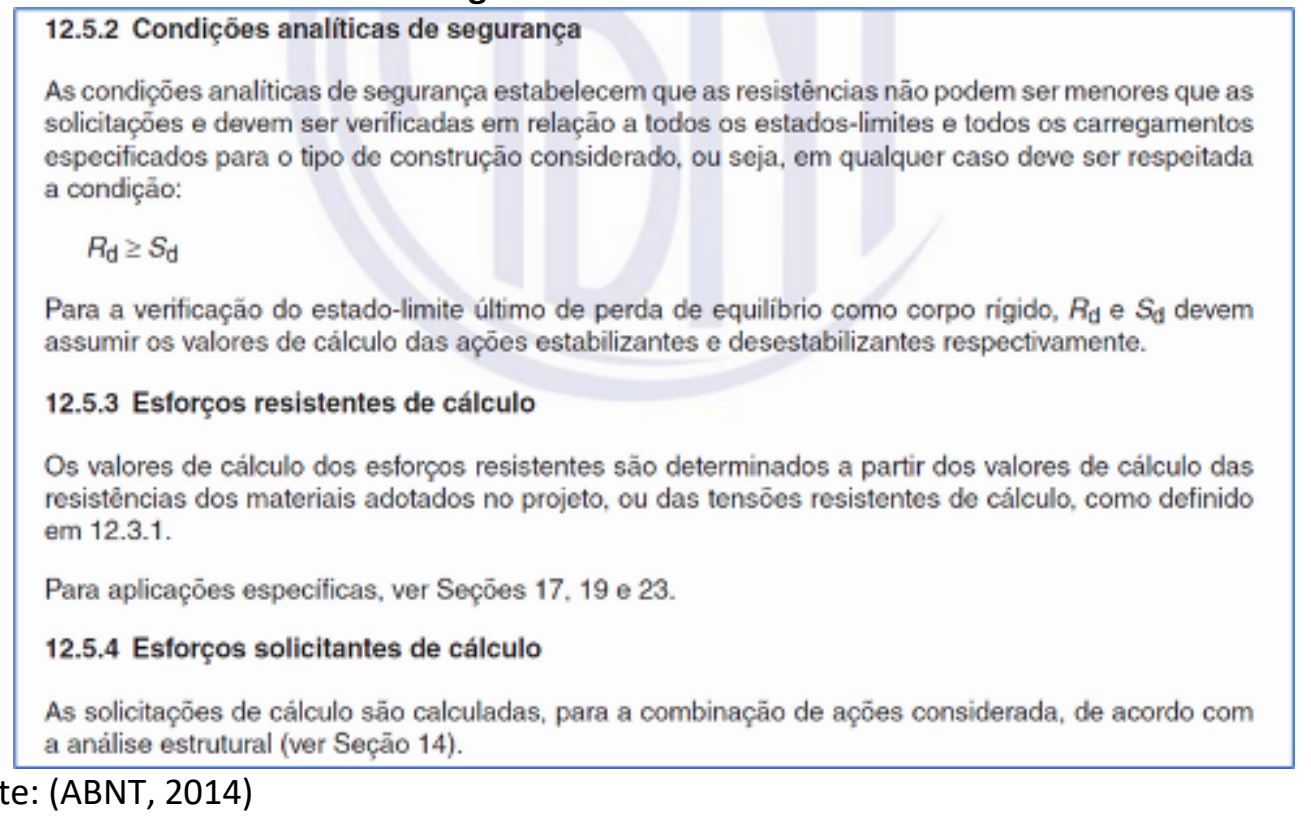

No estado limite último (ELU), os coeficientes de ponderação das ações nas combinações normais estão definidos na Tabela 11.1 da NBR 6118, também reproduzida a seguir:

Tabela 6 - Reprodução da Tabela 11.1 da NBR 6118:2014

\begin{tabular}{|c|c|c|c|c|c|c|c|c|}
\hline \multirow{3}{*}{$\begin{array}{l}\text { Combinações } \\
\text { de açōes }\end{array}$} & \multicolumn{8}{|c|}{ Açōes } \\
\hline & \multicolumn{2}{|c|}{$\begin{array}{l}\text { Permanentes } \\
\text { (g) }\end{array}$} & \multicolumn{2}{|c|}{$\begin{array}{l}\text { Variáveis } \\
\text { (q) }\end{array}$} & \multicolumn{2}{|c|}{$\begin{array}{c}\text { Protensăo } \\
\text { (p) }\end{array}$} & \multicolumn{2}{|c|}{$\begin{array}{c}\text { Recalques de } \\
\text { apoio } \\
\text { e retraçāo }\end{array}$} \\
\hline & $D$ & $F$ & $G$ & $T$ & $D$ & $F$ & $D$ & $F$ \\
\hline Normais & $1,4^{\text {a }}$ & 1,0 & 1,4 & 1,2 & 1,2 & 0,9 & 1,2 & 0 \\
\hline $\begin{array}{l}\text { Especiais ou } \\
\text { de construçăo }\end{array}$ & 1,3 & 1,0 & 1,2 & 1,0 & 1,2 & 0,9 & 1,2 & 0 \\
\hline Excepcionais & 1,2 & 1,0 & 1,0 & 0 & 1,2 & 0,9 & 0 & 0 \\
\hline $\begin{array}{l}\text { onde } \\
\text { Dé destaworá } \\
\text { a Para as cargas } \\
\text { cialmente as p }\end{array}$ & $\begin{array}{l}\text { Fé to } \\
\text { erman } \\
\text { molda }\end{array}$ & $\begin{array}{l}\text { ável, G } \\
\text { esse }\end{array}$ & $\begin{array}{l}\text { resent } \\
\text { vena v } \\
\text { ficients }\end{array}$ & $\begin{array}{l}\text { cargas } \\
\text { slidade. } \\
\text { de ser r }\end{array}$ & $\begin{array}{l}\text { iáveis } \\
\text { no op } \\
\text { zido pe }\end{array}$ & $\begin{array}{l}\text { jeral } 6 \\
\text { própri } \\
3 .\end{array}$ & $\begin{array}{l}\text { a term } \\
\text { s estr }\end{array}$ & espe- \\
\hline
\end{tabular}

Fonte: (ABNT, 2014)

\begin{tabular}{l|l|l|l|l|l|l} 
Projectus | Rio de Janeiro | & V.5 & N. 1 & P. $36-53$ & | & 2020
\end{tabular}


Portanto, para combinações de ações normais, o quociente entre o esforço resistente de cálculo e o esforço solicitante característico deve ser maior ou igual a 1,4 para que esteja comprovada a segurança da seção em estudo.

Cabe, aqui, uma importante consideração o valor do coeficiente de ponderação das ações permanentes, principalmente em relação ao peso próprio da estrutura. No caso presente, considerando se tratar de uma estrutura pronta e confirmadas no local algumas medidas dos elementos, em especial a espessura das lajes, consideramos perfeitamente possível e seguro adotar o valor entre 1,20 e 1,25 para este coeficiente. De fato, ainda que as normas brasileiras não abordem esta situação com clareza, o Comité Euro-Internacional du Béton (CEB) e a Fédération Internationale de la Précontrainte (FIP) trataram deste assunto em alguns dos diversos boletins publicados na década de 1980, afirmando que os coeficientes de majoração das cargas permanentes adotados nas verificações de segurança de estruturas existentes deveriam ser inferiores aos usuais, exatamente por ser possível tomar as medidas reais dos elementos.

Assim procedendo, considerando o fator 1,25 para o peso próprio e 1,40 para as demais ações, a segurança estaria satisfeita com o quociente entre o esforço resistente de cálculo e o esforço solicitante característico sendo maior ou igual a 1,3, valor adotado nas tabelas apresentadas a seguir.

$\mathrm{Na}$ tabela 7, na coluna direita, as células coloridas de vermelho indicam a necessidade de intervenções para a utilização dos pavimentos com necessária segurança. Basicamente, as seções com deficiência de armaduras se referem à flexão positiva

Em relação à situação atual, com apenas as cargas permanentes atuando, as lajes apresentam suficiente segurança.

Como forma de descrever sucintamente os resultados, a tabela 7 apresenta apenas as faixas críticas, cujos valores estão abaixo do fator de segurança definidos por normas. As demais faixas atenderam satisfatoriamente a segurança para utilização prevista, não sendo necessário intervenções nestas regiões.

Tabela 7 - Segurança das lajes dos pavimentos Tipo - Sentido transversal

\begin{tabular}{|c|c|c|c|c|c|c|c|c|c|c|c|c|c|c|c|c|c|c|}
\hline Direçă̄o & local & $\begin{array}{c}f_{p t} \\
(k g f j / \text { ont }\end{array}$ & $t_{6}$ & $\begin{array}{c}t_{6} \\
\left(\mathrm{log}^{6}[\mathrm{~cm})^{2}\right)\end{array}$ & $t_{10}$ & $b_{n} /\left(\mathrm{cm}^{\prime}\right)$ & $d(\mathrm{om})$ & $\mid A_{1}\left[\mathrm{~cm}^{1} / \mathrm{m}_{\mathrm{I}} \mid\right.$ & a & $\rho$ & $\beta_{4}$ & $\beta_{2}$ & $V_{1 u}[$ ffor $/ n]$ & $M_{\text {uan }}[$ ffon/min & 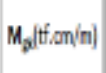 & $M_{2}[f / c m / \pi]$ & $M_{w} / M_{p}$ & $\mathrm{M}_{1} / \mathrm{M}_{\mathrm{g}}$ \\
\hline \multirow{5}{*}{ 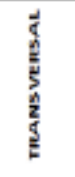 } & \multicolumn{18}{|c|}{ Flecio Positiva } \\
\hline & Fabe $2 A$ & 5000 & 4347,83 & 360 & 24,26 & 100 & 18,0 & 608 & 23.87 & $0,0,038$ & 21,66 & 0,847 & 505,3 & 360,9 & 267,4 & 393,2 & 189 & 1,29 \\
\hline & Faba 3A & 5000 & 0347,83 & 360 & 24229 & 100 & 18,0 & 7,67 & 2387 & $0,0,043$ & 9.83 & 0,943 & 566,0 & $4,4,3$ & 351,4 & 478,0 & $16 !$ & 1,18 \\
\hline & Faide $4 \mathrm{~A}$ & 9000 & 4347,83 & 360 & 24,23 & 100 & 18,0 & 7,67 & 23,87 & 0,0043 & 983 & 0,963 & 566,0 & 474,3 & 384,9 & 527,1 & 1,47 & 1,07 \\
\hline & Faba $5 \mathrm{~A}$ & 5000 & 4347,83 & 360 & 24,29 & 100 & 18,0 & $6,0,8$ & 8.87 & $0,0,038$ & 11,06 & 0,947 & 506,3 & 360,9 & 325,7 & 48,0 & 1.55 & 1,13 \\
\hline
\end{tabular}




\section{REFORÇO DAS LAJES (RESULTADOS E DISCUSSÕES)}

Conforme exposto no presente relatório, após verificação de segurança das lajes do pavimento tipo, constatou-se deficiências relevantes para flexão positiva em algumas regiões da laje, sendo recomendado intervenções nas mesmas.

Neste item será apresentado o memorial de cálculo para reforço das lajes do pavimento tipo com laminados de fibra de carbono. Como o procedimento segue no mesmo padrão nas demais faixas críticas do pano de laje, será apresentado o cálculo apenas da faixa 4A, no sentido de flexão positiva das armaduras transversais.

\subsubsection{Materiais}

- Concreto: Fck projeto $=300 \mathrm{kgf} / \mathrm{cm}^{2}$

$$
\text { Fck ensaios }=360 \mathrm{kgf} / \mathrm{cm}^{2} \rightarrow \mathrm{fcm}, \mathrm{we}=36 \times 1,20=43,2 \mathrm{MPa}
$$

- Aço: CA-50;

- Laminados CFRP E $\geq 165 \mathrm{GPa}$

\subsubsection{Geometria}

- Lajes em geral: $\mathrm{h}=22 \mathrm{~cm} / \mathrm{d}=18 \mathrm{~cm}$;

- Capitéis: $\mathrm{h}=42 \mathrm{~cm} / \mathrm{d}=38 \mathrm{~cm}$

\subsubsection{Definição do momento resistente da seção de interesse}

Antes de dimensionar o reforço em si, é necessário descobrir a seção resistente do elemento a qual está se analisando, para então ser comparado aos esforços solicitantes e verificar se o elemento atende ou não quanto aos critérios de segurança.

Sendo assim, para cálculo do momento resistente da seção de interesse, foi utilizada a metodologia abordada no livro (SANTOS, Lauro Modesto dos. Cálculo de concreto armado segundo a NB-1/76 e o CEB/72, São Paulo, Edgar Blucher, 1977.), e é apresentada logo abaixo:

$M_{\text {RES }}=A_{S} f y d \beta_{z} d$

Onde $\beta_{z}$ é obtido por meio da tabela F1, correlacionando o valor de $\beta_{4}$, que se dá por: 
$\beta_{4}=\frac{1}{\alpha \rho}$, sendo: $\alpha=\frac{\text { fyd }}{0,85 f c d}$ e $\rho=\frac{A s}{b d}$

Com os dados das lajes já conhecidos, bem como a disposição das armaduras, as informações foram inseridas nas fórmulas e os resultados apresentados na Tabela 7.

\subsubsection{Obtenção dos esforços via modelo computacional}

Utilizou-se o software TQS na versão V22.3. A análise do comportamento estrutural dos pavimentos foi realizada através de modelos de grelha ou pórtico plano. Nestes modelos as lajes foram integralmente consideradas, junto com vigas e os apoios formados pelos pilares existentes

Os esforços obtidos dos modelos estruturais dos pavimentos foram utilizados para o dimensionamento do reforço à flexão e cisalhamento.

Figuras 12 e 13 - Modelagem 3D (a esquerda) e Pórtico unifilar espacial (a direita). Ambos obtidos através do software TQS v22.3
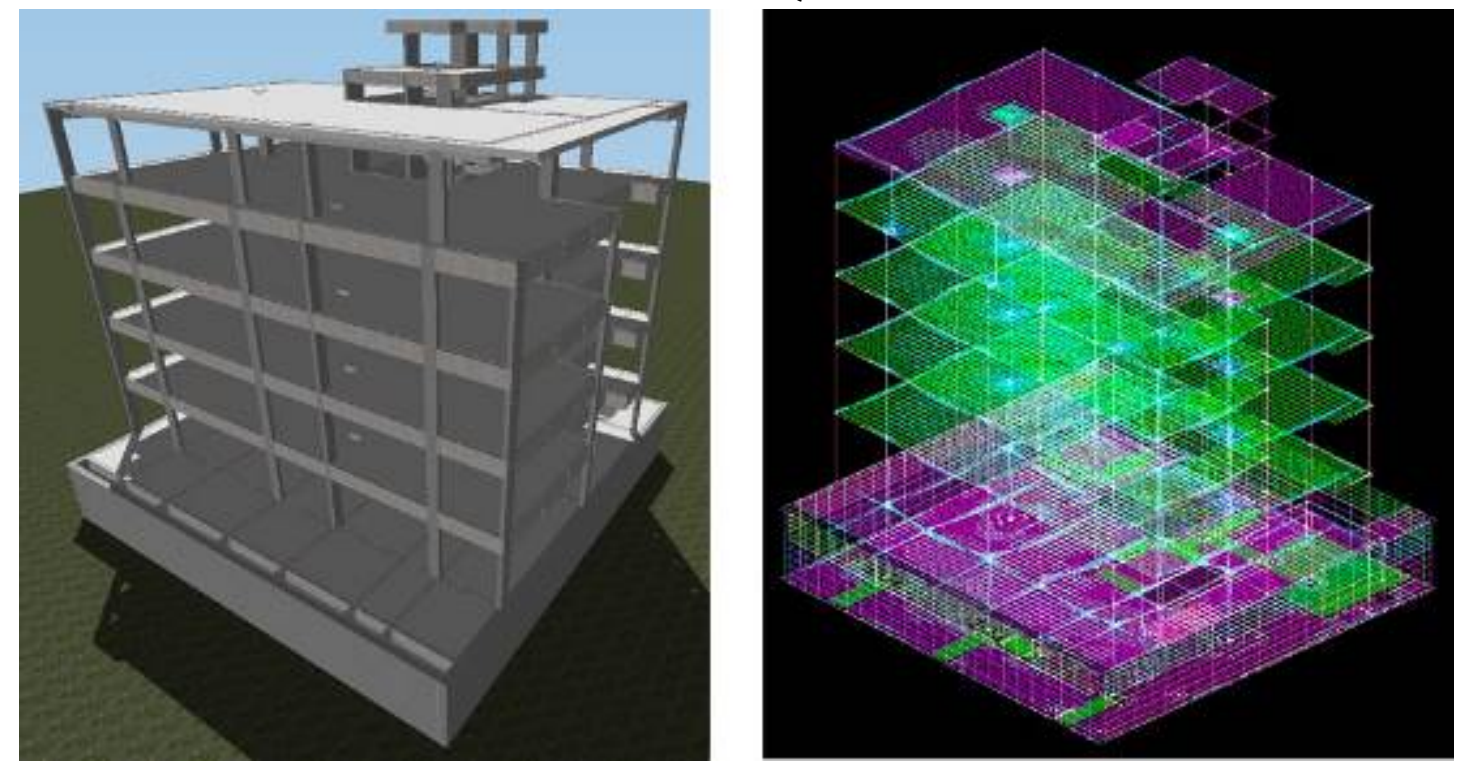

Fonte: (Autor)

Figura14 - Diagrama de momentos fletores característicos do pavimento tipo

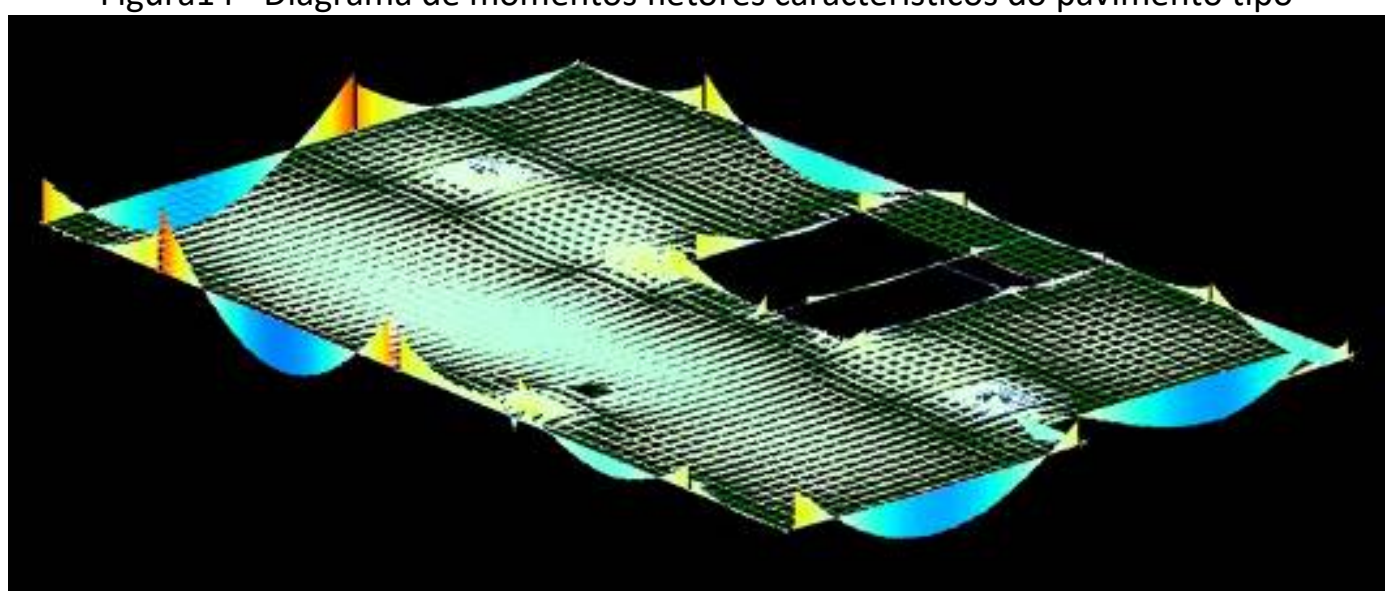

Fonte: (Autor) 


\subsubsection{Definição dos reforços necessários (Faixa 4A)}

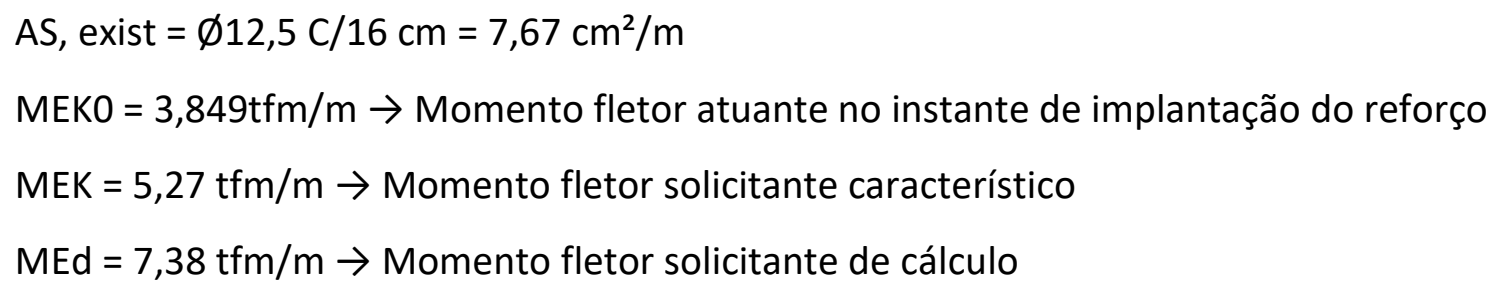

Adotando laminados 50 x 1,4 C/40 cm, têm-se:

$$
\begin{aligned}
& \mathrm{MRd}=10,16 \mathrm{tfm} / \mathrm{m}>7,38 \mathrm{tfm} / \mathrm{m} \\
& \text { oc,máx }=-15,87 \mathrm{MPa}<\text { olim =-21,6 MPa (OK!) } \\
& \text { oS, } \text { máx }=384,45 \mathrm{MPa}<\sigma l i m=400 \mathrm{MPa}(\mathrm{OK} \text { !) } \\
& \mathrm{MEd}, \mathrm{E}=2,00 \mathrm{tfm} / \mathrm{m} \\
& \mathrm{VEd}, \mathrm{A}=13,96 \mathrm{tf}
\end{aligned}
$$

\section{Resistência à Tração do Concreto:}

De acordo com a NBR 6118:2014 $\rightarrow \mathrm{fct}=1 / 3(\mathrm{fck}) 2 / 3=3,21 \mathrm{MPa}$

EUROCODE $2004 \rightarrow \mathrm{fct}=3,21 \mathrm{MPa}$

Adotado para fcsm = 2,5 MPa (tensão de aderência ao substrato)

$\mathrm{Ffd}, \mathrm{E}<\mathrm{Fbd}$, máx / 1,20 $\rightarrow$ OK!

\section{CONSIDERAÇÕES FINAIS}

Com base nos levantamentos de campo, nos resultados de ensaios e nos estudos feitos, pode-se chegar às seguintes conclusões quanto à segurança da estrutura das lajes dos pavimentos tipo para a atuação das cargas oriundas da utilização pretendida.

Antes de prosseguir, cabe ressaltar que houveram outras intervenções na estrutura, abordando outros elementos que não se limitassem às lajes, visto que durante as verificações, também se constatou resultados insatisfatórios para os mesmos.

Conforme resultados apresentados na Tabela 7, é notório a necessidade de reforços para flexão positiva no sentindo transversal das lajes, tendo em vista que o fator de segurança fica bem inferior ao limite estipulado de 1,30, quando se compara o momento resistente das seções de interesses com os momentos fletores solicitantes característicos. 
Já no caso da flexão positiva no sentido longitudinal, bem como os momentos fletores negativos em ambos os sentidos, não foram necessários dimensionamento de reforço, dado que a capacidade resistente das lajes é superior às solicitações de cálculo.

Dessa maneira, em virtude das limitações encontradas no local no que tange à evolução da obra em si, com instalações elétricas, instalações de dutos de ar condicionado e até rebaixo do teto com forro mineral já executadas, somadas as excelentes características mecânicas dos laminados, ainda que eles sejam mais adequados à reforços de flexão em elementos retilíneos, optou-se por solução o reforço estrutural em laminados de fibra de carbono.

Este estudo foi realizado também para despertar o interesse em engenheiros capacitados e ressaltar que o dimensionamento do reforço em fibra de carbono é uma solução inteiramente eficaz em estruturas de concreto armado, apresentam riscos menores de falhas executivas, fácil trabalhabilidade e acessível em determinadas situações. Ressaltando que, o dimensionamento do reforço estrutural bem como a execução deverão ser realizadas por profissionais qualificados, respeitando os limites impostos por normas técnicas e recomendações técnicas dos produtos utilizados.

\section{REFERÊNCIAS}

Associação Brasileira de Normas Técnicas. NBR 6118:2008, Projeto de estruturas de concreto Procedimento. ABNT, 2014.

. NBR 8800:2008, Projeto de estruturas de aço e de estruturas mistas de aço e concreto de edifícios. ABNT, 2008.

. NBR 6120:2018, Ações para o cálculo de estruturas de edificações. ABNT, 2019.

. NBR 6122:2019, Projeto e execução de fundações. ABNT, 2019.

. NBR 6123:1988, Força devido ao vento em edificações. ABNT, 1988.

. NBR 8681:2004, Ações e segurança nas estruturas - Procedimento. ABNT, 2004.

MACHADO, ARI DE PAULA. Manual de reforço das estruturas de concreto armado com fibras de carbono. VIAPOL, 2011.

SANTOS, LAURO MODESTO DOS. Cálculo de concreto armado segundo a NB-1/76 e o CEB/72. São Paulo. EDGAR BLUCHER, 1977. 